\title{
GC-MS analysis of two types of mixed oils, a comparison of composition and weathering patterns
}

\author{
S.J. Ho ${ }^{\mathrm{a}, \mathrm{b}, \mathrm{c}}$, C.Y. Wang ${ }^{\mathrm{b}, *}$, Y.M. Luo ${ }^{\mathrm{b}}$ \\ ${ }^{a}$ College of Geography and Planning, Ludong University, Yantai 264025, China \\ ${ }^{\mathrm{b}}$ Yantai Institute of Coastal Zone Research, Chinese Academy of Sciences, Yantai 264003, China \\ ' University of Chinese Academy of Sciences, Beijing 100049, China
}

\section{A R T I C L E I N F O}

\section{Article history:}

Received 16 January 2015

Revised 26 April 2015

Accepted 4 May 2015

Available online 14 May 2015

\section{Keywords:}

Oil spill fingerprint

Diagnostic ratios

Biomarkers

GC-MS

Simulation experiment

Mixed sources

\begin{abstract}
A B S T R A C T
In order to compare the effects of weathering on two types of mixed oil, simulated weathering experiments were performed. The first sample was a mixture of two fresh oils and the second sample was a mixture of one fresh oil and another oil sample that had undergone a serious weathering process. Comparative studies evaluated decay rates and changes in diagnostic ratios of some fingerprinting biomarkers. Results showed that the mixing process affected the weathering rate of some compounds in the oils and also that certain diagnostic ratios are more suitable for estimating mixing proportions. A $\mathrm{Pr} / n-\mathrm{C}_{17}$ versus $\mathrm{Ph} / n-\mathrm{C}_{18}$ plot can be used to identify the end-numbers of mixed oils and the $\left(C_{13}+C_{14}\right) /\left(C_{25}+C_{26}\right)$ ratio is a useful diagnostic ratio to detect the degree of weathering. Finally, hopane, sterane, and alkylated PAH fingerprints were found to give useful insights about the sources of the mixed oils.
\end{abstract}

(ㄷ) 2015 Elsevier Ltd. All rights reserved.

\section{Introduction}

Recent statistical data has shown a slightly increasing trend of large oil spills from tankers (ITOPF, 2014). These massive releases of oil pose a significant threat to marine and coastal ecosystems; not only because of the extensive environmental harm they cause, but also because of the economic damages associated with their consequences (Garza-Gil et al., 2006; McCrea-Strub et al., 2011). Therefore, tracing the liable sources of these pollutants, as a primary stage, as well as understanding their fate and behavior so as to assess their potential long-term impact on the environment is extremely important (Wang et al., 2004; Hayworth et al., 2015). The technique of chemical fingerprinting has been widely employed and is able to provide specific information on the chemical composition of a crude oil in order to link it to a suspected source (Stout et al., 2001; Wang and Fingas, 2003; Radović et al., 2014). However, field samples in most actual spills are multi-source oils, which confounds the chemical fingerprints of the spilled oils and by extension the candidate sources (Christensen and Tomasi, 2007; Douglas et al., 1996; McKenna et al., 2013). When an oil pollution incident may involve mixed sources, the liability must be carefully separated and allocated to

\footnotetext{
* Corresponding author.

E-mail address: cywang@yic.ac.cn (C.Y. Wang).
}

the different responsible parties (Kvenvolden et al., 1995; Li and Xiong, 2009; Kao et al., 2015). Though the crude oils and petroleum products in multi-source oils spills have distinct chemical fingerprints, these cannot be easily detected or recognized, especially if they have undergone a weathering process that can alter the chemical fingerprints. Hence, determining potential sources as well as qualifying or even quantifying the contribution from each source become a large challenge when the problem involves mixed oils.

Some end-member candidate oils collected after actual marine spill events may be either tar balls that have weathered for a long time or seriously weathered oils re-released after being deposited onto a sea bed. It is widely acknowledged that hydrocarbons are able to migrate through shallow marine sediment on the ocean floor at continental margins and form an oil layer on the ocean surface (Kvenvolden, 1993). Therefore, in addition to weathering, the mixing of the oil with the background contaminants could affect the inherent fingerprints of spilled oil in the marine environment (Stout and Wang, 2007). A severe challenge in spill interpretation may arise whenever oil residues from previous chronic pollution or other fresh oils are mixed in with oil spill samples that need to be analyzed. The question thus becomes how, over short weathering periods, the changes seen in chemical fingerprints are different when two fresh oils are the end members versus when the candidate end members area weathered sample (e.g. tar balls) 
and a fresh oil. To investigate this question, we have conducted a weathering simulation experiment on artificially mixed oils.

The major aims of this paper are, therefore: (i) to compare the chemical compositions of both mixed products, (ii) to assess how the mixed oils evolve over time (fifteen days) after being spilled under controlled conditions, and (iii) to select useful diagnostic ratios to evaluate weathering processes for mixed oils.

\section{Experimental}

\subsection{Weathering simulation experiment}

Two crude oil samples were collected from different oilfields, Shengli oilfield (oil-1) and Tarim oilfield (oil-2). The Shengli oil is a heavy crude oil with a density (at $20^{\circ} \mathrm{C}$ ) of $0.9551 \mathrm{~g} / \mathrm{cm}^{3}$ and a viscosity (at $50{ }^{\circ} \mathrm{C}$ ) of $96.63 \mathrm{mPa}$ s. The Tarim oil is a lighter crude oil with a density (at $20^{\circ} \mathrm{C}$ ) of $0.8259 \mathrm{~g} / \mathrm{cm}^{3}$ and a viscosity (at $50{ }^{\circ} \mathrm{C}$ ) of $14.3 \mathrm{mPa}$. Two oil mixtures were then prepared, the first, group FO, (made using two fresh oils) was a mixture of oil-1 and the fresh Tarim crude oil (oil-2-0). The second mixture, group $\mathrm{OO}$ (made using an older oil and a fresh oil) was prepared using oil-1 and an older Tarim crude oil sample (oil-2-1) that had passed an artificial weathering process for 210 days. Samples from each of the two groups were then prepared at different mixing proportions, weighed (around $5 \mathrm{~g}$ ), and poured into $50-\mathrm{ml}$ graduated centrifuge tubes. Appropriate volumes of dichloromethane (DCM) were added in order to dissolve all mixed samples under ultrasonic oscillation ( $180 \mathrm{~W}$, continuous mode) and

Table 1

Sample information of single-source and mixed oils.

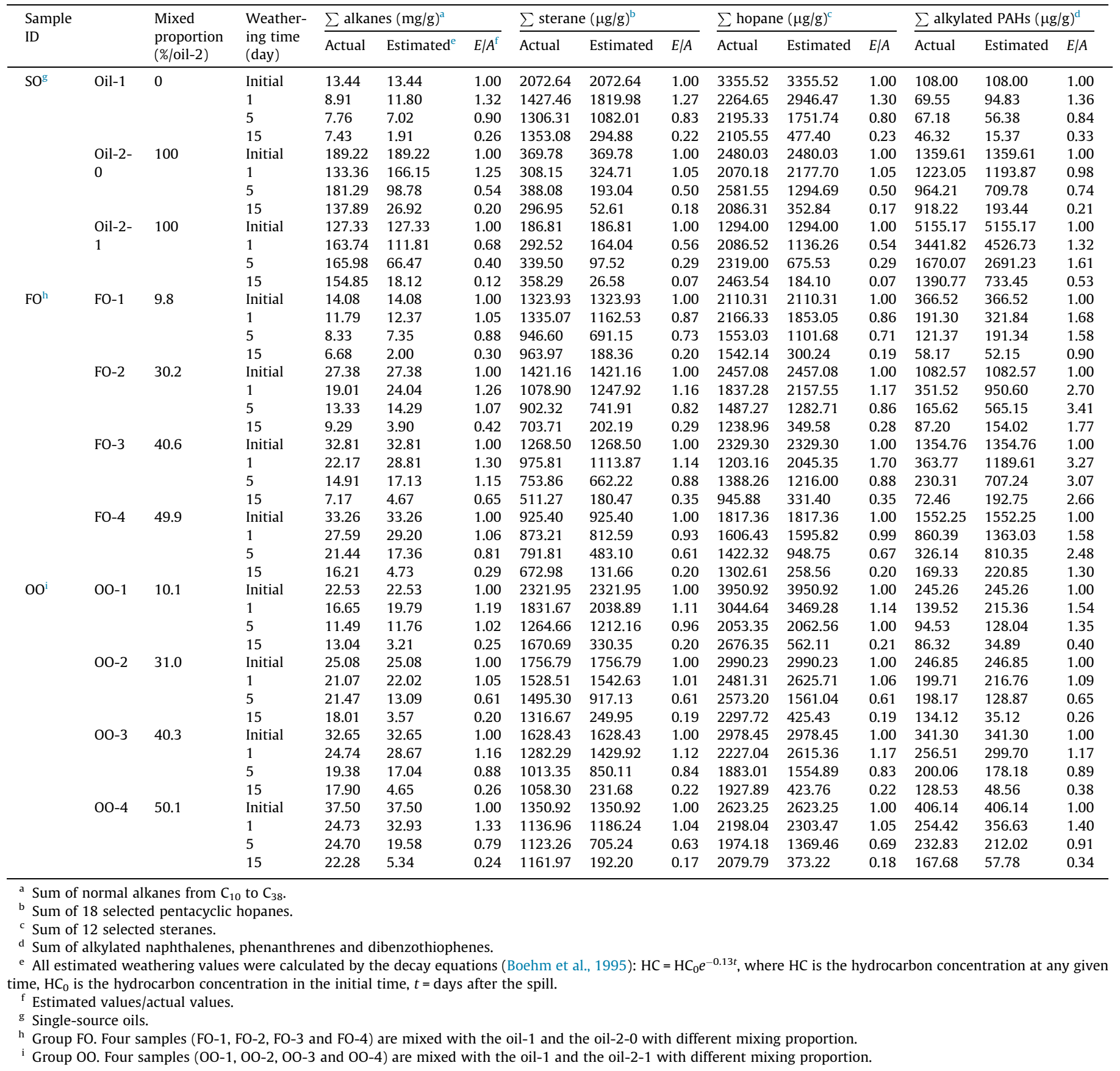


samples were then shaken for 5 min. The numbering system and the mixing proportions are listed in Table 1.

All mixed samples were then added to $400 \mathrm{ml}$ beakers containing approximately $200 \mathrm{ml}$ of seawater with an approximately $5 \mathrm{~cm}$ thick layer of sand at the bottom. Next the beakers were set in two tanks $(L * B * H=80 \mathrm{~cm} * 30 \mathrm{~cm} * 50 \mathrm{~cm}$, respectively) as seen in Fig. 1 . The beakers were then placed in a BOXUN SPX-400 IC environmental test chamber with settings of humidity at $70 \% \mathrm{RH}$, illumination at $12,000 \mathrm{LX}$, and temperature at $26^{\circ} \mathrm{C}$ during the day, and with settings of humidity at $60 \% \mathrm{RH}$, illumination at $0 \mathrm{LX}$, and temperature at $20^{\circ} \mathrm{C}$ at night, in order to simulate the summer climate of the Yellow Sea. For each of the single-source and mixed oils, the weathering times tested were 1,5 , and 15 days.

\subsection{Extraction, fractionation and instrumental analysis}

Oil samples were weighed (approximately 0.1-0.2 g) and then dissolved in $10 \mathrm{ml}$ of $\mathrm{n}$-hexane in $15 \mathrm{ml}$ centrifuge tubes. After ultrasonic oscillation for $15 \mathrm{~min}$, each of the oil sample extracts were dehydrated using anhydrous sodium sulfate (certified ACS grade), filtered through a $0.2 \mu \mathrm{m}$ nylon filter, and finally transferred to $5 \mathrm{ml} \mathrm{screw}$ cap auto-sampler vials. A mixture of internal standards composed of $50 \mu \mathrm{l}$ each of $10 \mathrm{mg} / \mathrm{l}$ tetracosane-d50 (Sigma-Aldrich Co. USA), 5- $\alpha$-androstane, and 4-terphenyl-d14 (both obtained from J\&K SCIENTIFIC Ltd. CHN) was injected into the final sample extracts just prior to GC-MS analysis.

Further sample treatment and analysis was performed according to previously described methods (Stout and Wang, 2007;

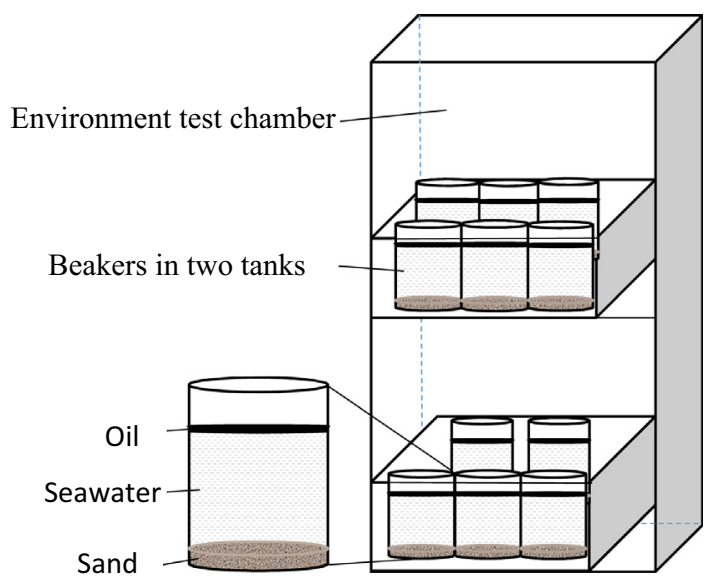

Fig. 1. Mimic diagram of the simulation test device.
CEN/TR 15522-2, 2012). Briefly, analysis was completed using a $6890 \mathrm{~N}$ gas chromatograph connected to a GC-5973 N mass spectrometer (energy $70 \mathrm{eV}, \mathrm{m} / \mathrm{z} 50-800$, and the source at $230^{\circ} \mathrm{C}$ and quadruple at $150{ }^{\circ} \mathrm{C}$ ) in the EI mode, equipped with a HP-5 capillary column $(50 \mathrm{~m} \times 0.32 \mathrm{~mm} \times 0.25 \mu \mathrm{m}$, Agilent Technologies, USA). The oven temperature was first held at $50{ }^{\circ} \mathrm{C}$ for $2 \mathrm{~min}$ and then programmed to rise from 50 to $300^{\circ} \mathrm{C}$ at a rate of $6{ }^{\circ} \mathrm{C} / \mathrm{min}$ and maintain the final temperature for $16 \mathrm{~min}$. Helium was used as the carrier gas at a flow rate of $1.0 \mathrm{ml} / \mathrm{min}$. The present $n$-alkanes were identified based on the retention time of the standards $\left(n \mathrm{C}_{10-40}\right.$, Sigma), and the concentrations of each $n$-alkane were calculated based on a standard calibration curve prepared for each corresponding standard compound.

\section{Results and discussions}

\subsection{Degradation rates and quantification of the mixed oils}

The exponential decay equation was used to estimate the weathering values for the oils (Boehm et al., 1995). The apparent decay-rate constants in nature vary from -0.008 to -0.01 day $^{-1}$ due to the various decay rates of different organic compounds (Yim et al., 2011). The average decay-rate constant $k$ for this work was set at $-0.13 \mathrm{day}^{-1}$, considering that actual values are almost equivalent to estimated values (Table 1 ). The average decay-rate constant $k$ represents an estimated decay-rate of $-12.19 \%$ day $^{-1}$. Colombo et al. (2005) had previously reported the decay-rate constants in soils relative to sediments $\left(-0.006\right.$ versus -0.003 day $^{-1}$, respectively). Even though dispersants were added to the weathering oil, the decay-rate constant $k$ for oils in sea water is only -0.008 day $^{-1}$ and -0.035 day $^{-1}$ for total alkanes and total aromatics, respectively. Venosa et al. (1996) studied the estimated decay-rate of a sandy beach with aerated soils for the control plots, and reported decay-rates of $-2.6 \%$ and $-2.1 \%$ day $^{-1}$ for total alkanes and total aromatics, respectively. A similar work showed a lower decay-rate for coastal marshes, with a rate of $-0.39 \%$ day $^{-1}$ observed for the total alkane pool (Turner et al., 2014). For the works mentioned, the decay-rate constants in the artificial weathering simulation experiments were lower than what has been observed in the natural environment. However, the decay rate in this experiment was observed to be faster than the weathering process in nature, and indicates that the conditions in this chamber are able to speed up the oil weathering process. One former study showed that evaporation, dissolution, and dispersion are the major oil weathering processes (Joo et al., 2013). Three factors (plenty of ventilation, constant illumination, and high temperature

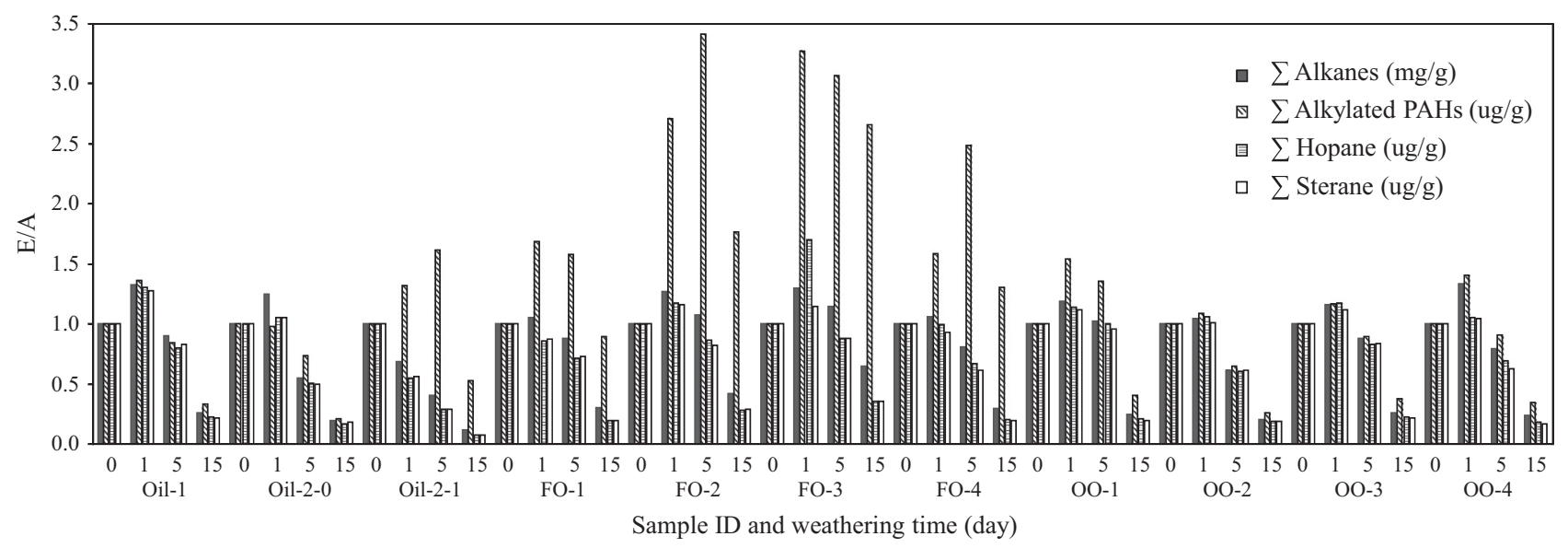

Fig. 2. Estimated values versus actual observed values of content of compounds in different oils. 
Table 2

Comparisons with the actual and estimated initial values of selected diagnostic ratios of mixed oils.

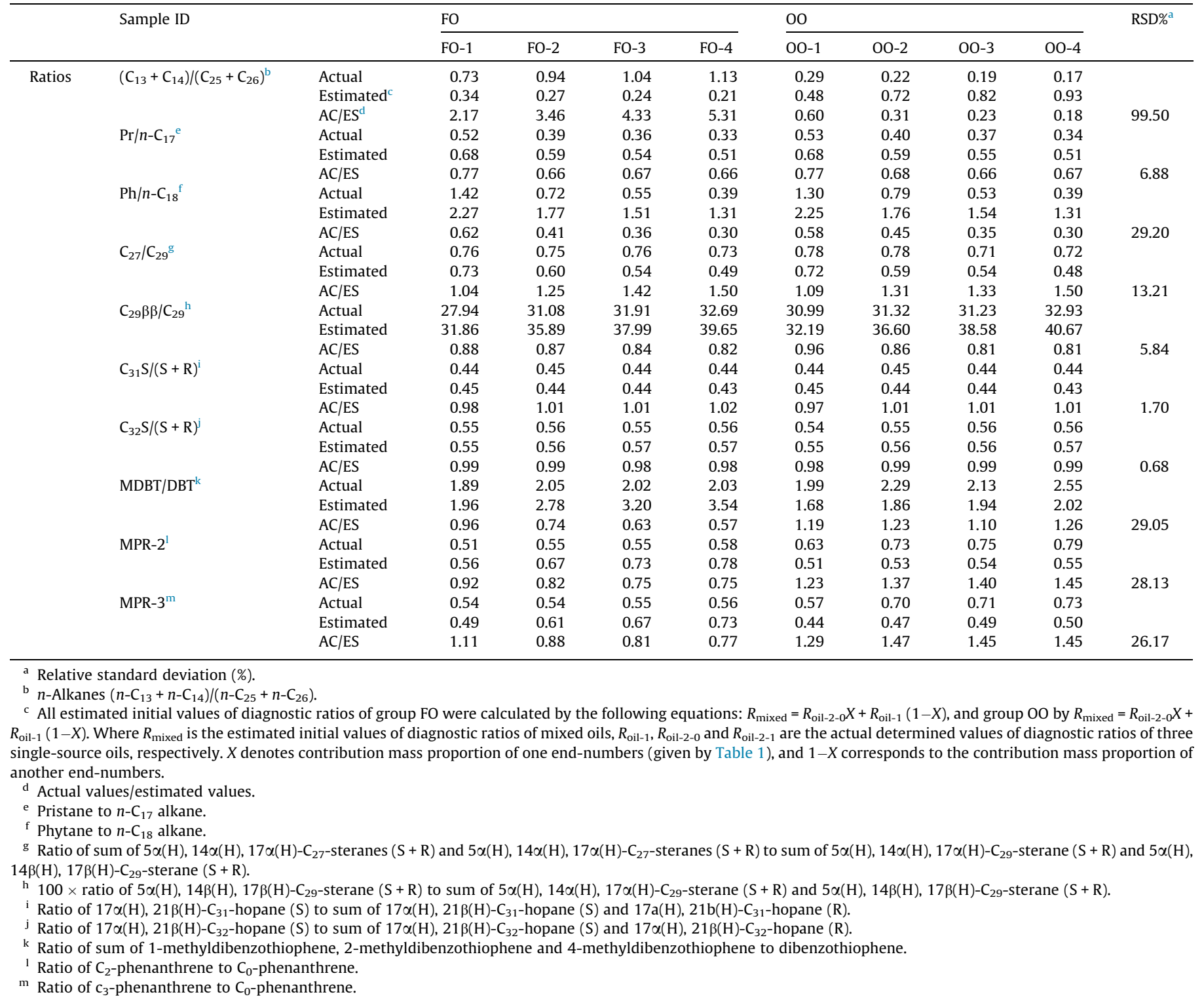

conditions) are able to influence these oil weathering processes and accelerate the oil decay rate in an environmental test chamber.

The large difference in decay rates between single-source oils and mixed oils are shown in Fig. 2. These results reveal that over time the ratios of the estimated values compared to the actual observed values $(E / A)$ for all oils becomes increasingly smaller, indicating that the decay due to the weathering process becomes slower overall. As can be seen from Fig. 2, oil-2-0 has a faster decay-rate for alkylated PAHs ( $E / A \geqslant 1$ over 1,5 , and 15 days) as compared to oil-1. In addition, the group FO has a faster decay-rate for alkylated PAHs than is seen in group 00. This most likely means that the mixing process is able to change the weathering rate of some compounds in oils.

By comparing the calculated values with the actual values of different diagnostic ratios (Table 2), useful diagnostic ratios estimating the mixed mass proportions can be obtained using the following principle: the relative deviation (RSD\%) of the ratios comparing actually determined values to the estimated values for the diagnostic ratios of all samples should be less than 5 . Therefore, in terms of a practical investigation of two suspected oil sources, some diagnostic ratios, such as $C_{31} S /(S+R)$ and $\mathrm{C}_{32} \mathrm{~S} /(\mathrm{S}+\mathrm{R})$ are most suitable for estimating mixing proportions.

\subsection{Biomarker fingerprints}

\subsection{1. n-Alkanes and isoprenoid fingerprints}

$n$-Alkanes and isoprenoid hydrocarbons are commonly used to characterize the source composition of spill oils (Wang and Fingas, 2003; Liu et al., 2009). Some diagnostic ratios, such as $\left(C_{13}+C_{14}\right) /\left(C_{25}+C_{26}\right)$, represent one of multiple weathering characteristics, evaporation in this case (Diez et al.,2007). Yim et al. (2011) used this ratio to categorize the oil weathering process into four stages: the initial weathering stage $\left(a\left(C_{13}+C_{14}\right) /\left(C_{25}+C_{26}\right)\right.$ ratio over 1.0), the moderate weathering stage (a $\left(C_{13}+C_{14}\right) /\left(C_{25}+C_{26}\right)$ ratio between 0.1 and 1.0$)$, the advanced weathering stage $\left(a\left(C_{13}+C_{14}\right) /\left(C_{25}+C_{26}\right)\right.$ ratio between 0.01 and $0.1)$, and the extreme weathering stage $\left(a\left(C_{13}+C_{14}\right) /\left(C_{25}+C_{26}\right)\right.$ ratio of less than 0.01). Fig. 3 and Table 3 show that the $\left(C_{13}+C_{14}\right) /\left(C_{25}+C_{26}\right)$ ratio measured for oil-2-1 changed the most dramatically out of the three single-source oils, most likely due to 


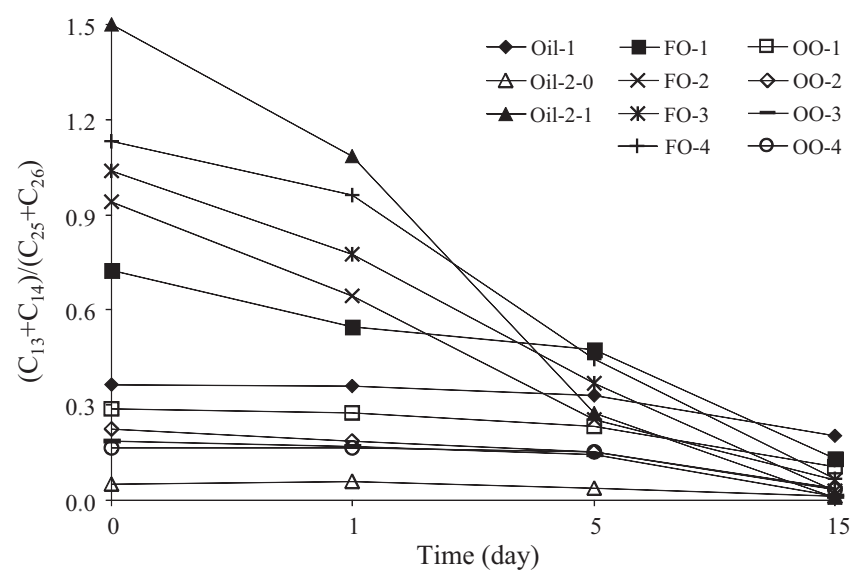

Fig. 3. Change mode of $\left(C_{13}+C_{14}\right) /\left(C_{25}+C_{26}\right)$ of oils. Refer to Table 2 for abbreviations. the fact that it is the lightest crude oil, and suggests that this oil has undergone an extensive transformation. Furthermore, it was also shown that the initial $\left(C_{13}+C_{14}\right) /\left(C_{25}+C_{26}\right)$ values of the samples in the two groups become increasingly closer to the initial $\left(C_{13}+C_{14}\right) /\left(C_{25}+C_{26}\right)$ value of oil- 1 as the mixing mass proportions of oil-1 increase. The $\left(C_{13}+C_{14}\right) /\left(C_{25}+C_{26}\right)$ ratios of the mixed oils are positively correlated to the proportion of oil-2-0 in the FO group. In contrast, there is a negative correlation between the $\left(C_{13}+C_{14}\right) /\left(C_{25}+C_{26}\right)$ ratio of mixed oils in the 00 group and the proportion of oil-2-1. The $\left(C_{13}+C_{14}\right) /\left(C_{25}+C_{26}\right)$ ratio of the 00 group mixed oils changed less significantly than for the FO group, indicating that the ratio of fresh oil mixed with an older oil has a lower $\left(C_{13}+C_{14}\right) /\left(C_{25}+C_{26}\right)$ ratio (lower than 0.3 ) and also changes only slightly during a short-term weathering process. Therefore, if the $\left(C_{13}+C_{14}\right) /\left(C_{25}+C_{26}\right)$ ratios measured for actual spill cases are larger than that of the potential source, the spill is most likely due to fresh oil. If, however, the $\left(C_{13}+C_{14}\right) /\left(C_{25}+C_{26}\right)$ ratio of a field

Table 3

Selected diagnostic ratios used for source identification of single-source and mixed oils.

\begin{tabular}{|c|c|c|c|c|c|c|c|c|c|c|c|c|c|}
\hline \multirow{2}{*}{$\begin{array}{l}\text { Sample } \\
\text { ID }\end{array}$} & \multirow{2}{*}{$\begin{array}{l}\text { Weathering time } \\
\text { (day) }\end{array}$} & & \multicolumn{11}{|c|}{ Diagnosis ratios $^{\mathrm{a}}$} \\
\hline & & & $\begin{array}{l}\left(C_{13}+C_{14}\right) / \\
\left(C_{25}+C_{26}\right) \\
\end{array}$ & $\begin{array}{l}\operatorname{Pr} / n- \\
\mathrm{C}_{17} \\
\end{array}$ & $\begin{array}{l}\mathrm{Ph} / n- \\
\mathrm{C}_{18}\end{array}$ & $\begin{array}{l}\mathrm{C}_{27} / \\
\mathrm{C}_{29}\end{array}$ & $\begin{array}{l}C_{29} \beta \beta / \\
C_{29} \\
\end{array}$ & $\begin{array}{l}\mathrm{C}_{31} \mathrm{~S} / \\
(\mathrm{S}+\mathrm{R}) \\
\end{array}$ & $\begin{array}{l}\mathrm{C}_{32} \mathrm{~S} / \\
(\mathrm{S}+\mathrm{R})\end{array}$ & $\begin{array}{l}(N+N 1) / \\
N 2^{\mathrm{b}}\end{array}$ & $\begin{array}{l}\text { MDBT/ } \\
\text { DBT }\end{array}$ & $\begin{array}{l}\text { MPR- } \\
2\end{array}$ & $\begin{array}{l}\text { MPR- } \\
3\end{array}$ \\
\hline \multirow[t]{12}{*}{ SO } & \multirow[t]{4}{*}{ Oil-1 } & Initial & 0.36 & 0.73 & 2.50 & 0.78 & 30.00 & 0.54 & 0.55 & 1.49 & 1.59 & 0.51 & 0.43 \\
\hline & & 1 & 0.36 & 0.72 & 2.59 & 0.83 & 29.94 & 0.54 & 0.55 & 1.47 & 1.66 & 0.51 & 0.44 \\
\hline & & 5 & 0.33 & 0.72 & 2.54 & 0.79 & 30.27 & 0.54 & 0.54 & 1.41 & 1.54 & 0.52 & 0.46 \\
\hline & & 15 & 0.20 & 0.75 & 2.55 & 0.78 & 27.87 & 0.56 & 0.52 & 1.37 & 1.68 & 0.49 & 0.42 \\
\hline & \multirow[t]{4}{*}{ Oil-2-0 } & Initial & 1.50 & 0.09 & 0.29 & 0.48 & 51.30 & 0.59 & 0.58 & 1.10 & 2.44 & 0.58 & 0.58 \\
\hline & & 1 & 1.09 & 0.09 & 0.28 & 0.48 & 52.88 & 0.59 & 0.57 & 0.61 & 2.48 & 0.58 & 0.57 \\
\hline & & 5 & 0.28 & 0.09 & 0.30 & 0.44 & 50.18 & 0.59 & 0.58 & 0.90 & 2.82 & 0.64 & 0.63 \\
\hline & & 15 & 0.01 & 0.12 & 0.25 & 0.43 & 51.68 & 0.59 & 0.58 & 1.12 & 3.22 & 0.86 & 0.88 \\
\hline & \multirow[t]{4}{*}{ Oil-2-1 } & Initial & 0.05 & 0.30 & 0.10 & 0.43 & 49.39 & 0.59 & 0.58 & 1.58 & 4.43 & 1.15 & 1.11 \\
\hline & & 1 & 0.06 & 0.27 & 0.08 & 0.40 & 50.11 & 0.60 & 0.59 & 1.10 & 4.19 & 1.05 & 1.03 \\
\hline & & 5 & 0.04 & 0.27 & 0.08 & 0.41 & 49.69 & 0.60 & 0.58 & 0.73 & 4.39 & 1.15 & 1.11 \\
\hline & & 15 & 0.01 & 0.30 & 0.10 & 0.39 & 50.37 & 0.59 & 0.59 & 1.10 & 5.07 & 1.26 & 1.20 \\
\hline \multirow[t]{16}{*}{ FO } & \multirow[t]{4}{*}{ FO-1 } & Initial & 0.73 & 0.52 & 1.42 & 0.76 & 27.94 & 0.56 & 0.55 & 1.19 & 1.89 & 0.51 & 0.54 \\
\hline & & 1 & 0.55 & 0.54 & 1.59 & 0.84 & 30.23 & 0.55 & 0.55 & 0.97 & 1.84 & 0.56 & 0.50 \\
\hline & & 5 & 0.48 & 0.55 & 1.54 & 0.79 & 30.33 & 0.55 & 0.55 & 0.96 & 1.84 & 0.56 & 0.50 \\
\hline & & 15 & 0.13 & 0.54 & 1.61 & 0.78 & 27.98 & 0.55 & 0.54 & 1.14 & 1.94 & 0.58 & 0.58 \\
\hline & \multirow[t]{4}{*}{ FO-2 } & Initial & 0.94 & 0.39 & 0.72 & 0.75 & 31.08 & 0.55 & 0.56 & 1.14 & 2.05 & 0.55 & 0.54 \\
\hline & & 1 & 0.64 & 0.41 & 0.72 & 0.74 & 30.15 & 0.55 & 0.56 & 0.77 & 2.04 & 0.58 & 0.55 \\
\hline & & 5 & 0.25 & 0.41 & 0.75 & 0.77 & 28.54 & 0.55 & 0.55 & 1.16 & 2.15 & 0.60 & 0.58 \\
\hline & & 15 & 0.06 & 0.44 & 0.74 & 0.83 & 31.24 & 0.56 & 0.55 & 1.08 & 2.54 & 0.71 & 0.68 \\
\hline & \multirow[t]{4}{*}{ FO-3 } & Initial & 1.04 & 0.36 & 0.55 & 0.76 & 31.91 & 0.56 & 0.55 & 1.13 & 2.02 & 0.55 & 0.55 \\
\hline & & 1 & 0.77 & 0.39 & 0.58 & 0.94 & 38.72 & 0.56 & 0.55 & 0.81 & 1.98 & 0.58 & 0.55 \\
\hline & & 5 & 0.37 & 0.39 & 0.58 & 0.78 & 31.75 & 0.56 & 0.55 & 0.86 & 2.05 & 0.58 & 0.56 \\
\hline & & 15 & 0.03 & 0.40 & 0.61 & 0.78 & 29.44 & 0.56 & 0.55 & 1.36 & 2.65 & 0.74 & 0.69 \\
\hline & \multirow[t]{4}{*}{ FO-4 } & Initial & 1.13 & 0.33 & 0.39 & 0.73 & 32.69 & 0.56 & 0.56 & 1.10 & 2.03 & 0.58 & 0.56 \\
\hline & & 1 & 0.96 & 0.35 & 0.44 & 0.76 & 29.68 & 0.56 & 0.56 & 0.82 & 2.05 & 0.57 & 0.56 \\
\hline & & 5 & 0.44 & 0.36 & 0.42 & 0.69 & 29.65 & 0.57 & 0.55 & 0.81 & 2.32 & 0.59 & 0.57 \\
\hline & & 15 & 0.07 & 0.38 & 0.44 & 0.76 & 32.56 & 0.57 & 0.55 & 0.93 & 2.68 & 0.74 & 0.70 \\
\hline \multirow[t]{16}{*}{$\mathrm{OO}$} & \multirow[t]{4}{*}{ OO-1 } & Initial & 0.29 & 0.53 & 1.30 & 0.78 & 30.99 & 0.56 & 0.54 & 1.54 & 1.99 & 0.63 & 0.57 \\
\hline & & 1 & 0.28 & 0.52 & 1.45 & 0.77 & 30.97 & 0.55 & 0.55 & 1.47 & 1.85 & 0.69 & 0.62 \\
\hline & & 5 & 0.23 & 0.54 & 1.47 & 0.86 & 30.37 & 0.56 & 0.55 & 1.36 & 1.85 & 0.65 & 0.66 \\
\hline & & 15 & 0.10 & 0.55 & 1.52 & 0.78 & 28.21 & 0.56 & 0.52 & 1.42 & 2.09 & 0.71 & 0.71 \\
\hline & \multirow[t]{4}{*}{ OO-2 } & Initial & 0.22 & 0.40 & 0.79 & 0.78 & 31.32 & 0.55 & 0.55 & 1.49 & 2.29 & 0.73 & 0.70 \\
\hline & & 1 & 0.19 & 0.42 & 0.75 & 0.77 & 28.72 & 0.56 & 0.58 & 1.40 & 2.36 & 0.76 & 0.68 \\
\hline & & 5 & 0.15 & 0.41 & 0.76 & 0.77 & 30.87 & 0.55 & 0.55 & 1.27 & 2.17 & 0.79 & 0.74 \\
\hline & & 15 & 0.04 & 0.43 & 0.79 & 0.73 & 30.01 & 0.56 & 0.56 & 1.48 & 2.41 & 0.90 & 0.81 \\
\hline & \multirow[t]{4}{*}{$00-3$} & Initial & 0.19 & 0.37 & 0.53 & 0.71 & 31.23 & 0.56 & 0.56 & 1.55 & 2.13 & 0.75 & 0.71 \\
\hline & & 1 & 0.17 & 0.36 & 0.56 & 0.74 & 29.08 & 0.57 & 0.55 & 1.47 & 2.42 & 0.77 & 0.71 \\
\hline & & 5 & 0.15 & 0.39 & 0.54 & 0.77 & 32.08 & 0.56 & 0.55 & 1.21 & 2.52 & 0.81 & 0.74 \\
\hline & & 15 & 0.01 & 0.41 & 0.55 & 0.74 & 31.35 & 0.55 & 0.55 & 1.63 & 3.07 & 0.85 & 0.82 \\
\hline & \multirow[t]{4}{*}{ OO-4 } & Initial & 0.17 & 0.34 & 0.39 & 0.72 & 32.93 & 0.56 & 0.56 & 1.53 & 2.55 & 0.79 & 0.73 \\
\hline & & 1 & 0.16 & 0.36 & 0.47 & 0.75 & 31.93 & 0.56 & 0.56 & 1.51 & 2.39 & 0.77 & 0.73 \\
\hline & & 5 & 0.15 & 0.36 & 0.49 & 0.76 & 29.20 & 0.57 & 0.55 & 1.33 & 2.65 & 0.83 & 0.77 \\
\hline & & 15 & 0.03 & 0.39 & 0.48 & 0.74 & 29.15 & 0.57 & 0.55 & 1.45 & 2.83 & 0.85 & 0.92 \\
\hline
\end{tabular}

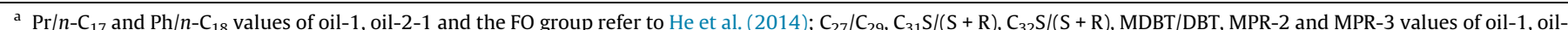
2-1 and the FO group refer to He et al. (2015).

${ }^{b}$ Ratio of the sum of $C_{0}$-naphthalene and $C_{1}$-naphthalene versus $C_{2}$-naphthalene. 
sample is less than that of a potential source, fresh oil from the source may have become mixed with previously spilled older oil.

The ratio of $\mathrm{Pr} / n-\mathrm{C}_{17}$ versus $\mathrm{Ph} / n-\mathrm{C}_{18}$ has been widely used to identify the changes over time seen for organic matter and organic matter maturation and even recover the individual depositional environments (Connan and Cassou, 1980; Peters et al., 1999; Baban and Ahmed, 2013). From a cross plot of $\operatorname{Pr} / n-C_{17}$ versus $\mathrm{Ph} / n-\mathrm{C}_{18}$ (Fig. 4A), mixing was clearly seen in the $\mathrm{Pr} / n-\mathrm{C}_{17}$ versus $\mathrm{Ph} / n-\mathrm{C}_{18}$ double plot, where oil- 1 and oil-2-0, and oil- 1 and oil-2-1 are the endpoints of the two group oils, respectively. There is a significant $(P<0.05)$ linear relationship between $\mathrm{Pr} / n-\mathrm{C}_{17}$ and $\mathrm{Ph} / n-\mathrm{C}_{18}$ as shown in Fig. $4 \mathrm{~A}$. Samples from group FO and the $O O$ group displayed little change in the ratios of $\mathrm{Pr} / n-\mathrm{C}_{17}$ versus $\mathrm{Ph} / n-\mathrm{C}_{18}$, with values ranging from 0.33 to 0.55 and 0.39 to 1.52 , respectively. Furthermore the samples with the same mass proportions of oil-1 (e.g. FO-1 and 0O-1) were quite close to each other, indicating a similar degree of weathering for these samples and that the two mixed oil groups are closely related. The weathering process did not cause large scattering in the data plots, indicating that the influence of the mixed
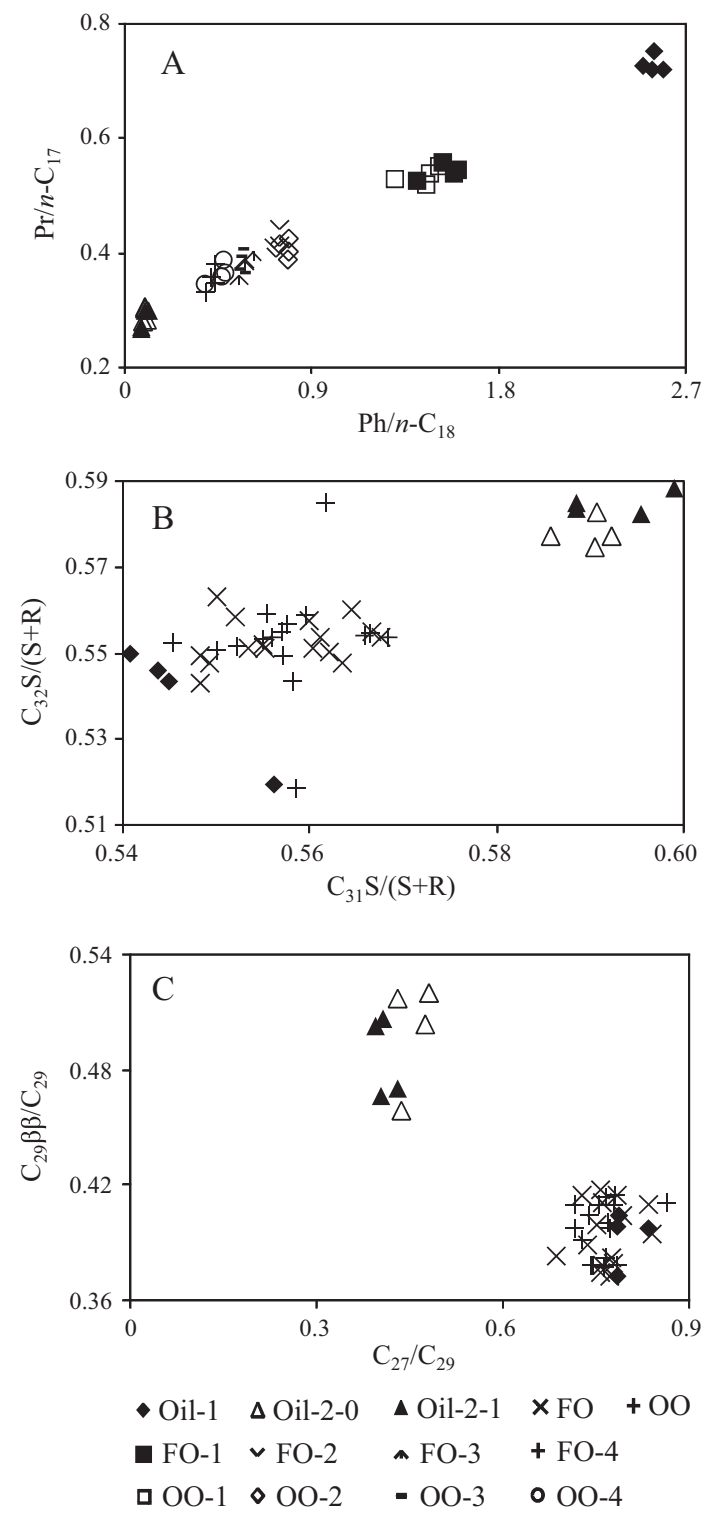

Fig. 4. Cross-plots of biomarker parameters. (A) $\mathrm{Ph} / n-\mathrm{C}_{18}$ versus $\mathrm{Pr} / n-\mathrm{C}_{17}$. (B) $\mathrm{C}_{31} \mathrm{~S} /$ $(S+R)$ versus $C_{32} S /(S+R)$. (C) $C_{27} / C_{29}$ versus $C_{29} \beta \beta / C_{29}$. proportion on the degree of change of $\mathrm{Pr} / n-\mathrm{C}_{17}$ and $\mathrm{Ph} / n-\mathrm{C}_{18}$ is larger than seen from the degree of weathering. An increase in the $\mathrm{Pr} / n-\mathrm{C}_{17}$ and $\mathrm{Ph} / n-\mathrm{C}_{18}$ of oil always indicates a relative increase in the degree of oil biodegradation (Formolo et al., 2008). The result that $\operatorname{Pr} / n-C_{17}$ and $\mathrm{Ph} / n-\mathrm{C}_{18}$ values of each oil examined in this work did not change significantly indicates that biodegradation is not a dominant factor in such a short-term weathering process.

\subsubsection{Hopane, sterane and PAHs fingerprints}

In general, because they are high molecular weight organic compounds, hopane and sterane biomarkers are more resistant to degradation than $n$-alkanes and isoprenoids (Barakat et al., 2002; Suneel et al., 2013). In this work, the influence of the weathering process on the oils' $\mathrm{C}_{31} \mathrm{~S} /(\mathrm{S}+\mathrm{R})$ and $\mathrm{C}_{32} \mathrm{~S} /(\mathrm{S}+\mathrm{R})$ ratios are related to hopane and the $C_{27} / C_{29}$ and $C_{29} \beta \beta / C_{29}$ ratios are related to sterane, and are of interest because they own qualities that can be used to differentiate oil sources (Table 3). As shown in Table 3 , the combined ratios of the selected pairs of terpanes and steranes, especially the ratios of $C_{31} S /(S+R)$ and $C_{32} S /(S+R)$, were apparently independent of weathering effects and therefore very useful in identifying spilled oil sources. Oil-2-0 and oil-2-1 samples have similar $C_{31} S /(S+R)$ ratio values, and are lower than the values measured for the two groups of mixed oils and oil-1. The plots of the two groups in Fig. 4B are similar to each other and lie between the values of the three single sources in the double plot (Fig. 4B). The $\mathrm{C}_{31} \mathrm{~S} /(\mathrm{S}+\mathrm{R})$ and $\mathrm{C}_{32} \mathrm{~S} /(\mathrm{S}+\mathrm{R})$ values of the two groups are increasingly near to the values of oil- 1 as the proportion of oil-1 increases. The double ratio plots of $\mathrm{C}_{31} \mathrm{~S} /(\mathrm{S}+\mathrm{R})$ and $\mathrm{C}_{32} \mathrm{~S} /(\mathrm{S}+\mathrm{R})$ could be used to identify sources and further define the mixing of oil- 1 and oil-2-0, as well as oil-1 and oil-2-1 (Fig. 4B). Oil-2-0 and oil-2-1 have similar $C_{27} / C_{29}$ and $C_{29} \beta \beta / C_{29}$ values that are higher than the values of the two group mixed oils and oil-1 (Fig. 4C). The values of the two groups of mixed oils are also close together and almost between the values of the three single sources in the double plot (Fig. 4C). The fact that the $C_{27} / C_{29}$ and $C_{29} \beta \beta / C_{29}$ values of the mixed oils (including their short-term weathered oils) are close to the values measured for oil-1 reveals that some
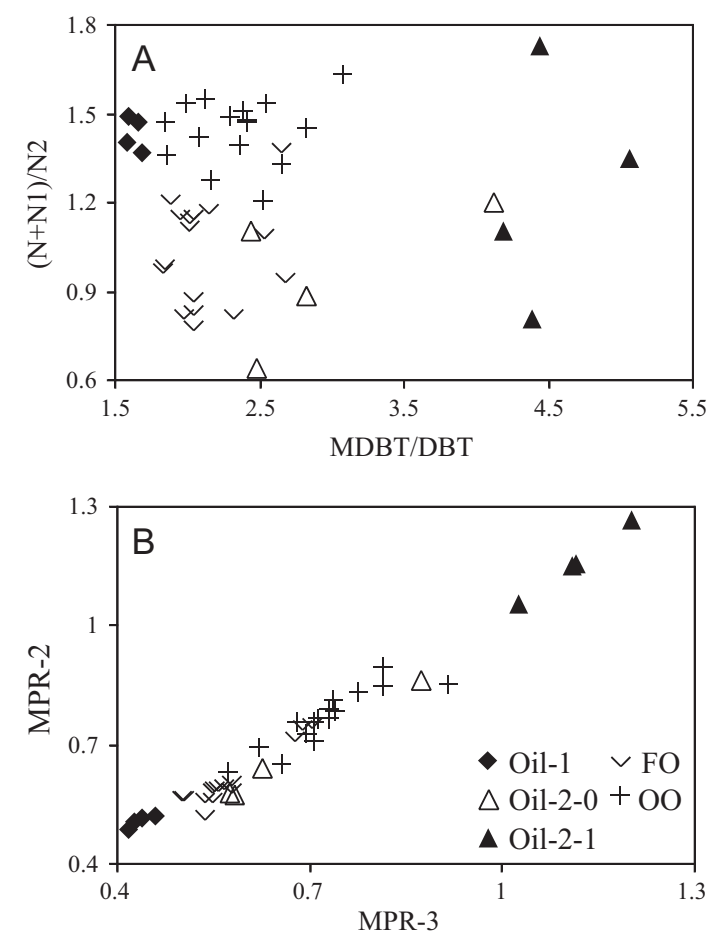

Fig. 5. Double ratio plots using alkylated phenanthrenes and dibenzothiophenes. (A) MDBT/DBT versus methylnaphthalenes [ $(N+N 1) / N 2]$, (B) MPR-3 versus MPR-2. 
diagnostic ratios of mixed oils could be used as excellent indicators to identify their individual oil source endpoints.

Alkylated homologues of polycyclic aromatic hydrocarbons have high stability and are much more easily quantified than $n$-alkanes (Wang and Fingas, 1995; Ezra et al., 2000). The cross-plot of the two ratios MDBT/DBT and $(N+N 1) / N 2$ was adopted to describe the variations in abundance of naphthalene and dibenzothiophene compounds (Fig. 5A). The 00 group oils have higher values of the sum of $C_{0}$-naphthalene and $C_{1}$-naphthalene versus $C_{2}$-naphthalene than the $\mathrm{FO}$ group oils. The $\mathrm{OO}$ group oils have similar values for the ratio of MDBT/DBT as the group FO oils. High values for the ratio of $(N+N 1) / N 2$ as well as the comparable ratio values measured for the MDBT/DBT ratio in both group $\mathrm{OO}$ and group FO oils suggest that the MDBT/DBT ratios in the mixed oils are more stable over time than the $(N+N 1) / N 2$ ratio. Generally, indicators in the naphthalene and phenanthrene series (e.g. the MPR-2 and MPR-3 indices) are used in the identification of oil spills. Even though the MPR-2 index, similar to other conventional naphthalenes including the methyldibenzothiophene and phenanthrene indices, is able to separate oil-1 from two mixed oil groups after the weathering process, it can also differentiate between oil-1 and the other samples in the same group (Fig. 5B). As seen in the cross plot of MPR-2 and MPR-3 (Fig. 5B), mixing is also clear in the MPR-3 versus MPR-2 double plot, where oil-1 and oil-2-0, and oil-1 and oil-2-1 are the endpoints of two oil groups, respectively. The seriously weathered single-source sample (oil-2-1) displayed more dramatic changes than oil-2-0 for the ratios of MPR-2 and MPR-3 with values in the range of $1.05-1.26$ and $1.03-1.20$, respectively. This response can identify oil-2-1 in both of the mixed oil groups (Fig. 5B). Data plots of MPR-2 and MPR-3 values for oil-2-0 are mixed with the data plots of the two mixed groups (ranging from 1.56 to 1.95 ) and in between the values of oil-1 and oil-2-1 (ranging from 0.51 to 0.86 and 0.50 to 0.92 , respectively.) Based on this data, it seems that oil- 1 and oil-2-1 are the representative end-members of the two group oils. A significant correlation coefficient value of $0.86(p<0.05, n=44)$ was measured between MPR-2 and MPR-3, and shows that there is a significant relationship between MPR-2 and MPR-3.

\section{Conclusion}

In this study, simulated weathering experiments were performed on two oils and two oil mixtures containing a series of artificially mixed oils in order to detect the differences in identification and quantification between these mixed oils after a short term weathering process. This artificial oil weathering experiment conducted in a controlled environmental test chamber was able to simulate the weathering process which occurs in nature. The decay-rates for a single day in the environmental test chamber are nearly equal to the decay-rate for a month under natural conditions, allowing the test chamber to accelerate the oil weathering process. The decay rates for single-source oils versus the mixed oils are different, and the mixing process changed the weathering rates of some individual compounds in the oils. The decay-rate constant under the artificial weathering simulation experiment was lower than the decay-rate constants observed in the natural environment, indicating that the decay rates measured during this experiment were higher than the natural weathering process.

To determine whether an accidental oil spill mixed with other oils, a short-term artificial weathering test is needed. In this test, the resulting $\mathrm{Pr} / n-\mathrm{C}_{17}$ versus $\mathrm{Ph} / n-\mathrm{C}_{18}$ plot can identify whether the spilled oil samples are correlated to one single oil that always appears as one of the end-numbers and the major oil contained in the spill. The $\left(C_{13}+C_{14}\right) /\left(C_{25}+C_{26}\right)$ ratio can be used to clarify whether the mixed oils are older than the spill being investigated. Multiple biomarker fingerprints (e.g. $C_{27} / C_{29}, \quad C_{29} \beta \beta / C_{29}$, $\mathrm{C}_{31} \mathrm{~S} /(\mathrm{S}+\mathrm{R}), \mathrm{C}_{32} \mathrm{~S} /(\mathrm{S}+\mathrm{R}), \mathrm{MPR}-2$, and MPR-3) can give additional information about the source of the spilled oil. The changes to degradation rates of oils in a short-term weathering test can also indicate characteristics useful to distinguish the different sources of spilled oils. Finally, some diagnostic ratios, such as $C_{31} S /(S+R)$ and $\mathrm{C}_{32} \mathrm{~S} /(\mathrm{S}+\mathrm{R})$, are most suitable to use in order to estimate mixing proportions.

\section{Acknowledgements}

This work was financially supported by the National Natural Science Foundation of China (Grant No. 41206089) and the "1-3-5" Research Program of Yantai Institute of Coastal Zone Research, Chinese Academy of Sciences (Nos. Y254021031 and Y455011031).

\section{References}

Baban, D.H., Ahmed, S.M., 2013. Vitrinite reflectance as a tool for determining level of thermal maturity for the Upper Jurassic Naokelekan and Barsarin Formations in Sargelu location, Kurdistan Region, NE Iraq. Arab. J. Geosci., 1-9

Barakat, A.O., Mostafa, A.R., Qian, Y., Kennicutt, M.C., 2002. Application of petroleum hydrocarbon chemical fingerprinting in oil spill investigations-gulf of Suez, Egypt. Spill Sci. Technol. Bull. 7, 229-231.

Boehm, D., Page, D.S., Gilfillan, E.S., Stubblefield, W.A., Harner, E.J., 1995. Shoreline ecology program for Prince William Sound, Alaska, following the Exxon Valdez oil spill: Part 2. Chemistry and toxicology, vol. 1219. ASTM Special Technical Publication, pp. 347-397.

CEN/TR 15522-2, 2012. Oil spill identification. Waterborne petroleum and petroleum products. Part 2: Analytical methodology and interpretation of results based on GC-FID and GC-MS low resolution analyses. CEN, Technical Report.

Christensen, J.H., Tomasi, G., 2007. Review: practical aspects of chemometrics for oil spill fingerprinting. J. Chromatogr. A 1169, 1-22.

Colombo, J.C., Barreda, A., Bilos, C., Cappelletti, N., Migoya, M.C., Skorupka, C., 2005. Oil spill in the Río de la Plata estuary, Argentina: 2-hydrocarbon disappearance rates in sediments and soils. Environ. Pollut. 134 (2), 267-276.

Connan, J., Cassou, A.M., 1980. Properties of gases and petroleum liquids derived from terrestrial kerogen at various maturation levels. Geochim. Cosmochim. Acta 44, 1-23.

Diez, S., Jover, E., Bayona, J.M., Albaiges, J., 2007. Prestige oil spill. III. Fate of a heavy oil in the marine environment. Environ. Sci. Technol. 41, 3075-3082.

Douglas, G.S., Bence, A.E., Prince, R.C., McMillen, S.J., Butler, E.L., 1996. Environmental stability of selected petroleum hydrocarbon source and weathering ratios. Environ. Sci. Technol. 30 (7), 2332-2339.

Ezra, S., Feinstein, S., Pelly, I., Bauman, D., Miloslavsky, I., 2000. Weathering of fuel oil spill on the east Mediterranean coast, Ashdod, Israel. Org. Geochem. 31, 1733-1741.

Formolo, M.J., Salacup, J.M., Petsch, S.T., Martini, A.M., Nusslein, K., 2008. A new model linking atmospheric methane sources to Pleistocene glaciation via methanogenesis in sedimentary basins. Geology 36, 139-142.

Garza-Gil, M.D., Prada-Blanco, A., Vazquez-Rodriguez, M.X., 2006. Estimating the short-term economic damages from the prestige oil spill in the Galician fisheries and tourism. Ecol. Econ. 58 (4), 842-849.

Hayworth, J.S., Clement, T.P., John, G.F., Yin, F., 2015. Fate of deepwater horizon oil in Alabama's beach system: understanding physical evolution processes based on observational data. Mar. Pollut. Bull. 90 (1), 95-105.

He, S.J., Wang, C.Y., Han, B., Yu, H.J., Zhou, T., 2014. Effect of short-term weathering on mixtures with two different mixing oils. Mar. Sci. 38 (12), 69-77 (in Chinese).

He, S.J., Wang, C.Y., Han, B., Yu, H.J., 2015. Effect of short time weathering on biomarker ratios of terpanes, steranes and PAHs in two different mixing oils. Haiyang Xuebao 37 (2), 1-10 (in Chinese).

ITOPF (International Tanker Owners Pollution Federation), 2014. Oil Tanker Spill Statistics <http://www.itopf.com/knowledge-resources/data-statistics/ statistics/>.

Joo, C., Shim, W.J., Kim, G.B., Ha, S.Y., Kim, M., An, J.G., Yim, U.H., 2013. Mesocosm study on weathering characteristics of Iranian heavy crude oil with and without dispersants. J. Hazard. Mater. 248, 37-46.

Kao, N.H., Su, M.C., Fan, J.R., Chung, Y.Y., 2015. Identification and quantification of biomarkers and polycyclic aromatic hydrocarbons (PAHs) in an aged mixed contaminated site: from source to soil. Environ. Sci. Pollut. Res., 1-18

Kvenvolden, K.A., 1993. Gas hydrates-geological perspective and global change. Rev. Geophys. 31, 173-187.

Kvenvolden, K.A., Hostettler, F.D., Carlson, P.R., Rapp, J.B., Threkleld, C.N., Warden, A., 1995. Ubiquitous tar balls with a California source signature on the shorelines of Prince William Sound, Alaska. Environ. Sci. Technol. 29, 26842694. 
Li, Y., Xiong, Y.Q., 2009. Identification and quantification of mixed sources of oil spills based on distributions and isotope profiles of long-chain n-alkanes. Mar. Pollut. Bull. 58, 1868-1873.

Liu, X., Wang, Z., Ma, X.D., Ding, L., Xu, H.Z., Yao, Z.W., 2009. Principal component analysis and distribution of paraffinic hydrocarbons in crude oils produced in Asia and Africa. Environ. Pollut. Control 31, 41-45 (In Chinese).

McCrea-Strub, A., Kleisner, K., Sumaila, U.R., Swartz, W., Watson, R., Zeller, D., Pauly, D., 2011. Potential impact of the deepwater horizon oil spill on commercial fisheries in the Gulf of Mexico. Fisheries 36, 332-336.

McKenna, A.M., Nelson, R.K., Reddy, C.M., et al., 2013. Expansion of the analytical window for oil spill characterization by ultrahigh resolution mass spectrometry: beyond gas chromatography. Environ. Sci. Technol. 47 (13), 7530-7539.

Peters, K.E., Fraser, T.H., Amris, W., Rustanto, B., Hermanto, E., 1999. Geochemistry of crude oils from eastern Indonesia. Am. Assoc. Pet. Geol. Bull. 83, 1927-1942.

Radović, J.R., Aeppli, C., Nelson, R.K., Jimenez, N., Reddy, C.M., Bayona, J.M., Albaigés, J., 2014. Assessment of photochemical processes in marine oil spill fingerprinting. Mar. Pollut. Bull. 79 (1), 268-277.

Stout, S.A., Uhler, A.D., McCarthy, K.J., 2001. A strategy and methodology for defensibly correlating spilled oil to source candidates. Environ. Forensics 2, 87-98.

Stout, S.A., Wang, Z.D., 2007. Chemical fingerprinting of spilled or discharged petroleum-methods and factors affecting petroleum fingerprints in the environment. In: Wang, Z.D., Stout, S.A. (Eds.), Oil Spill Environmental Forensics: Fingerprinting and Source Identification. Academic Press, Burlington, MA, pp. 1-45.

Suneel, V., Vethamony, P., Zakaria, M.P., Naik, B.G., Prasad, K.V.S.R., 2013. Identification of sources of tar balls deposited along the Goa coast, India, using fingerprinting techniques. Mar. Pollut. Bull. 70 (1), 81-89.

Turner, R.E., Overton, E.B., Meyer, B.M., Miles, M.S., Hooper-Bui, L., 2014. Changes in the concentration and relative abundance of alkanes and PAHs from the deepwater horizon oiling of coastal marshes. Mar. Pollut. Bull. 86 (1), 291-297.

Venosa, A.D., Suidan, M.T., Wrenn, B.A., et al., 1996. Bioremediation of an experimental oil spill on the shoreline of Delaware Bay. Environ. Sci. Technol. 30 (5), 1764-1775.

Wang, Z.D., Fingas, M., 1995. Differentiation of the source of spilled oil and monitoring of the oil weathering process using gas chromatography-mass spectrometry. J. Chromatogr. A 712, 321-343.

Wang, Z.D., Fingas, M.F., 2003. Development of oil hydrocarbon fingerprinting and identification techniques. Mar. Pollut. Bull. 47 (9-12), 423-452.

Wang, Z.D., Fingas, M., Lambert, P., Zeng, G., Yang, C., Hollebone, B., 2004 Characterization and identification of the Detroit River mystery oil spill (2002). J. Chromatogr. A 1038, 201-214.

Yim, U.H., Ha, S.Y., An, J.G., Won, J.H., Han, G.M., Hong, S.H., Kim, M., Jung, J.H., Shim, W.J., 2011. Fingerprint and weathering characteristics of stranded oils after the Hebei Spirit oil spill. J. Hazard. Mater. 197, 60-69. 